\title{
Effect of oil impregnation on water repellency, dimensional stability and mold susceptibility of thermally modified European aspen and downy birch wood
}

\author{
Sheikh Ali Ahmed ${ }^{1} \cdot$ Tom Morén $^{2} \cdot$ Margot Sehlstedt-Persson $^{2} \cdot$ Åsa Blom ${ }^{1}$
}

Received: 24 August 2016/ Accepted: 20 October 2016/Published online: 24 November 2016

(c) The Author(s) 2016. This article is published with open access at Springerlink.com

\begin{abstract}
Conventional chemical wood preservatives have been banned or restricted in some applications due to human and animal toxicity and their adverse impact on the surrounding environment. New, low-environmental-impact wood treatments that still provide effective protection systems are needed to protect wood. Thermal modification of wood could reduce hygroscopicity, improve dimensional stability and enhance resistance to mold attack. The aim of this study was to investigate if these properties enhanced in thermally modified (TM) wood through treatments with oils. In this study, TM European aspen (Populus tremula) and downy birch (Betula pubescens) wood were impregnated with three different types of oil: water-miscible commercial Elit Träskydd (Beckers oil with propiconazole and 3-iodo-2-propynyl butylcarbamate, IPBC), a pine tar formulation and $100 \%$ tung oil. The properties of oil-impregnated wood investigated were water repellency, dimensional stability and mold susceptibility. The treated wood, especially with pine tar and tung oil, showed an increase in water repellency and dimensional stability. However, Beckers oil which contains biocides like propiconazole and IPBC showed better protection against mold
\end{abstract}

Electronic supplementary material The online version of this article (doi:10.1007/s10086-016-1595-y) contains supplementary material, which is available to authorized users.

Sheikh Ali Ahmed

sheikh.ahmed@lnu.se

1 Department of Forestry and Wood Technology, Faculty of Technology, Linnaeus University, Georg Lückligs Plats 1, 35195 Växjö, Sweden

2 Division of Wood Science and Engineering, Department of Engineering Sciences and Mathematics, Luleå University of Technology, Campus Skellefteå, Forskargatan 1, 93187 Skellefteå, Sweden compared with pine tar and tung oil. To enhance the dimensional stability of the wood, pine tar and tung oil can be used, but these oil treatments did not significantly improve mold resistance rather sometimes enhanced the mold growth, whereas a significant anti-mold effect was observed on Beckers oil treated samples.

Keywords Thermal modification - Oil impregnation . Dimensional stability $\cdot$ Durability $\cdot$ Mold

\section{Introduction}

In the past several decades, a number of methods to thermally modified wood have been successfully developed. In Europe, five processes are currently available at the industrial scale, including ThermoWood ${ }^{\circledR}$ (or Premium wood) using steam in Finland; the Perdure process (BOIS PERDURE), which is conducted in a steam atmosphere in France; the Retification process using nitrogen (Retiwood) in France; the Plato process (Plato ${ }^{\circledR} \mathrm{WOOD}$ ) in an aqueous environment at super-atmospheric pressures in the Netherlands; and an oilheat treatment (Menz Holz ${ }^{\circledR}$ ) in Germany. All these processes are used to improve wood properties by reducing hygroscopicity, improving dimensional stability and enhancing resistance against biological attack by modifying the chemical structure of the wood at temperatures ranging from 160 to $260{ }^{\circ} \mathrm{C}$ [1-4]. The extent to which the wood properties are modified after the thermal treatment depends on the method, the wood species, inherent wood properties, the type and condition of the heating gas and the treatment schedules. Of these factors, temperature has the strongest effect on the properties of the thermally modified (TM) wood $[5,6]$. The available - $\mathrm{OH}$ groups in the hemicellulose have the most significant effect on the hygroscopicity of wood. 
Thermal treatment decreases the number of accessible $-\mathrm{OH}$ groups, resulting in a reduced water adsorption and an increase in the dimensional stability $[6,7]$.

The decay resistance of treated wood depends on several factors, such as the treatment method, wood species, whether the wood is sapwood or heartwood and the exposure conditions. An example is oil-heat treated wood, which has a noticeably lower mass loss due to fungal attack compared to air-heat-treated wood [8]. The reasons behind this decay resistance are the formation of new compounds from the polymeric wood constitutes as well as the reduction in hemicellulose content, hygroscopicity and compounds essential for fungal growth, such as starch, fatty acids and lipids [2, 3]. However, thermal modification combined with oil can provide more effective protection than single treatment methods alone $[8,9]$. In previous studies [10-12], authors attempted to develop a simple but effective method to impregnate oils in TM wood and focused on alternative wood treatments and processes in accordance with European legislation on wood preservatives, which banned most compounds that are toxic to humans, animals and the environment. Thus, investigation was done on the impregnation of TM wood with environmentally friendly wood preservatives. Thermal modification of wood processed by the Technical Research Centre of Finland (VTT) or by the Danish company Wood Treatment Technology (WTT) method follows mainly three phases: (1) high-temperature drying, (2) heat treatment and (3) cooling. To impregnate efficiently, proposed change was in the post-treatment with oil in phase 3 , occurring just after the thermal modification in phase 2 . The still hot samples are submerged in room temperature oil for simultaneous cooling and impregnation (illustration of this method can be found as an electronic supplementary material). A number of studies on the biodegradation of TM wood by fungi have been carried out to determine better protection methods $[4,13,14]$. However, only limited attempts have been made to test the durability of TM wood against mold [15, 16]. Several factors are involved in the onset of mold in different wood products, such as the moisture content of the wood, the relative humidity (RH), favorable ambient temperatures and climate stability [17, 18]. Wood cells contain compounds such as sugar, starch and nitrogenous compounds that further influence the severity/intensity of mold growth [17, 19]. As wood products are prone to developing mold depending on the ambient environmental conditions, durability tests are important to ensure the aesthetics of the wood products, the reduction of health hazards and the service life of wood.

In this study, two important Swedish hardwood species, aspen and birch, commercially TM by the WTT method, were taken under consideration. At the laboratory scale, three types of oils were impregnated in different wood samples and the water repellency, dimensional stability and mold susceptibility were investigated. Overall, this study provides a significant amount of information regarding the effects of thermal modification and oil impregnation on the moisture properties and mold susceptibility of these two important Swedish hardwood species.

\section{Experimental}

\section{Source of wood sample and oil impregnation}

Oil-impregnated samples from previous experiments were used in this study [11]. That started with commercial TM (at $170{ }^{\circ} \mathrm{C}$ for $2.5 \mathrm{~h}$ ) and non-TM European aspen (Populus tremula L.) (ca. $27 \times 165 \times 4000 \mathrm{~mm}$ ) and downy birch (Betula pubescens Ehrh.) boards (ca. $27 \times 92 \times 4000 \mathrm{~mm}$ ) collected from Thermoplus (Arvidsjaur, Sweden). The average oven-dry densities of TM aspen and birch were 459 and $561 \mathrm{~kg} \mathrm{~m}^{-3}$, whereas it was 452 and $577 \mathrm{~kg} \mathrm{~m}^{-3}$, respectively, for non-TM samples. Samples were impregnated with three different types of oil: (a) a water-miscible commercial product, Elit Träskydd (Beckers, Stockholm, Sweden), which contains additives such as propiconazole (0.6\%), 3-iodo-2-propynyl butylcarbamate (IPBC, 0.3\%) and modified linseed oil as binders and water as a solvent; (b) commercially produced pine tar, boiled linseed oil and turpentine (Claessons Trätjära $\mathrm{AB}$, Göteborg, Sweden) at a volume ratio of 1:4:2, respectively; and (c) commercial $100 \%$ tung oil (Pelard AB, Stockholm, Sweden). The oils (a), (b) and (c) are referred to as Beckers, pine tar and tung oil, respectively, in the following text.

Three boards of each species were planed, and three endmatched samples from each TM and non-TM samples were prepared. The sample dimensions for oil impregnation were $25 \times 90 \times 300 \mathrm{~mm}$. The samples were free from any visible defects (knots, cracks etc.), and were numbered consecutively. Three matched TM and non-TM samples from each species (aspen and birch) for each of the three treatments (Beckers, pine tar and tung oil) to produce a total of 36 samples, were used for impregnation. The samples were heated at $170{ }^{\circ} \mathrm{C}$ for $1 \mathrm{~h}$ in a conventional dry oven to reach the target temperature, $170{ }^{\circ} \mathrm{C}$ (as collected TM samples were commercially treated at this temperature). Due to this treatment, the extent of thermo-degradation for wood samples was not taken under consideration. The still-hot samples were quickly submerged in room temperature oil for simultaneous impregnation and cooling for $2 \mathrm{~h}$. Because the wood is preheated prior to impregnation, whatever air that is contained within the cell cavities and voids becomes hot and expands. Immersing the hot wood in room temperature oil causes the rapid contraction of the air within the cell cavities and voids, resulting in the solution being drawn up into the 
wood void structures. After soaking, excess oil was gently blotted away from the surfaces using paper towels, and the sample masses were recorded using a balance to the nearest $0.01 \mathrm{~g}$. The retention was calculated as

$R\left(\mathrm{~kg} \mathrm{~m}^{-3}\right)=1000 \mathrm{G} / \mathrm{V}$,

where $G$ is the mass (in $\mathrm{g}$ ) of the oil absorbed by the sample and $V$ is the volume (in $\mathrm{cm}^{3}$ ) of the sample.

\section{Water repellency and dimensional stability}

Two sets of samples of aspen and birch with final dimensions of $25 \times 25 \times 10 \mathrm{~mm}$ (radial $\times$ tangential $\times$ longitudinal) were sawed from boards with different treatments. Three types of oil-impregnated samples were fabricated from the TM and non-TM material. Unimpregnated samples were also fabricated from the TM and non-TM material to produce a total of 16 treatments. Unimpregnated aspen and birch samples from non-TM material were used as reference (control) samples. Five samples were fabricated for every treatment, each set consisting of a total of 80 samples. The samples were placed in an oven at $50{ }^{\circ} \mathrm{C}$ for $72 \mathrm{~h}$ to obtain constant masses. The drying temperature was kept low $\left(50{ }^{\circ} \mathrm{C}\right)$ to prevent the exudation of the oil. One set of samples was conditioned in a climate chamber maintained at $20{ }^{\circ} \mathrm{C}$ and $65 \% \mathrm{RH}$ to reach equilibrium moisture content (EMC). Then, the moisture excluding efficiency (MEE) was calculated as follows:

$\operatorname{MEE}(\%)=100 \times\left(E_{c}-E_{t}\right) / E_{c}$,

where $E_{c}$ and $E_{t}$ are the EMC of the control and oil treated samples, respectively. To determine the water uptake capacity and swelling properties, the samples were oven-dried at $50{ }^{\circ} \mathrm{C}$ for $72 \mathrm{~h}$ and submerged in distilled water at $21{ }^{\circ} \mathrm{C}$ for periods of 1, 3, 6, 12, 24, 48, 96, 192, 384 and $768 \mathrm{~h}$. The distilled water was replaced after every soaking interval. After each saturation period, the masses and volumes were recorded to measure water absorption (WA; defined as the absorbed water divided by the dried mass) and volumetric swelling coefficient $(S)$. The volume was determined by the immersion method; the wood samples were weighed while immersed and suspended in water. The water repellent efficiency (WRE) and antiswelling efficiency (ASE) were estimated after $768 \mathrm{~h}$ of soaking based on the $\mathrm{WA}_{\mathrm{t}}$ and $S_{t}$ of the treated samples relative to the $\mathrm{WA}_{\mathrm{c}}$ and $S_{c}$ of control, respectively:

$\operatorname{WRE}(\%)=100 \times\left(\mathrm{WA}_{c}-\mathrm{WA}_{t}\right) / \mathrm{WA}_{c}$

$\operatorname{ASE}(\%)=100 \times\left(S_{c}-S_{t}\right) / S_{c}$

The ASE of the TM and control samples impregnated with oil was calculated from the $S$ values of the unimpregnated TM and control samples, respectively. The volumetric swelling coefficient was calculated from
$S(\%)=100 \times\left(V_{w}-V_{d}\right) / V_{d}$,

where $V_{w}$ is the volume of the wood after wetting and $V_{d}$ is the volume of the wood in the dried sample before wetting.

\section{Wet-dry cyclic test}

To simulate the effects of weathering related to the waterleaching resistance, wet-dry cycles were performed on the second set of samples to calculate the volumetric swelling coefficients $(S)$ and relative weight loss percentage (WL). The WL of the sample is defined as the mass loss due to the removal of the oil and water-soluble components in the wood. One cycle consisted of submerging the samples in distilled water within an evacuated desiccator (ca. $20 \mathrm{mmHg}$ ) according to Rowell and Ellis [20]. The vacuum was maintained for $30 \mathrm{~min}$ and released over $1 \mathrm{~h}$ before being applied again for $30 \mathrm{~min}$ and then released for $24 \mathrm{~h}$. The samples were then dried at $50{ }^{\circ} \mathrm{C}$ for $72 \mathrm{~h}$ to attain a constant weight. The wet-dry cycling was repeated 5 times. Water was replaced with fresh distilled water after every cycle. The WL of the sample is defined as

$\mathrm{WL}(\%)=100 \times\left(W_{i}-W_{n}\right) / W_{n}$,

where $W_{i}$ is the initial dry weight before soaking and $W_{n}$ is the dry weight after the $n$th cycle.

\section{Accelerated mold test}

An accelerated laboratory mold test in a ARCTEST ARC 1500 climate chamber (Arctest Oy, Espoo, Finland) was performed using the same methodology described in Ahmed et al. [12]. TM and non-TM samples from each species (aspen and birch) for each oil treatments (Beckers, pine tar and tung oil) with three replications to produce 36 samples and with four replications, unimpregnated TM and non-TM wood from each species (aspen and birch) to produce 16 samples, were used for the accelerated mold test. The samples $(25 \times 90 \times 200 \mathrm{~mm})$ were suspended in the upper part of the chamber from supporting bars with the long dimension set horizontal and the flat surface set vertical and parallel to the other sample surfaces with approximately $15 \mathrm{~mm}$ gap between the randomly ordered samples. The temperature and RH in the chamber were set to be $27{ }^{\circ} \mathrm{C}$ and $92 \%$, respectively.

Three pine sapwood pieces from the previous experiment, infected with mold mainly from the Aspergillus, Rhizopus, Penicillium along with various other genus, were placed in the lower part of the climate chamber as the source of mold inocula [12]. After a 21-day incubation period, the experiment was stopped due to abundant mold growth on some of the sample surfaces. Both flat surfaces of each sample were evaluated and graded (on a 0-6 scale) by a method described in a previous study [21]. Two 
Table 1 Various moisture-related properties of the aspen and birch wood samples after treatment with oils (values in parenthesis indicate standard deviations)

\begin{tabular}{|c|c|c|c|c|c|c|}
\hline \multirow[t]{2}{*}{ Wood type } & \multirow[t]{2}{*}{ Oil type } & \multirow[t]{2}{*}{ Uptake $\left(\mathrm{kg} \mathrm{m}^{-3}\right)$} & \multicolumn{2}{|c|}{ Test at $65 \% \mathrm{RH}$} & \multicolumn{2}{|c|}{ Water-soaked test after $768 \mathrm{~h}$ of soaking } \\
\hline & & & $\operatorname{EMC~}(\%)$ & $\operatorname{MEE}(\%)$ & WRE $(\%)$ & ASE $(\%)$ \\
\hline Aspen & Tung oil & $267.1( \pm 0.9)$ & $6.7( \pm 0.3)$ & 30.7 & 65.5 & 15.3 \\
\hline TM-aspen & & $245.0( \pm 25.6)$ & $3.7( \pm 0.4)$ & 61.9 & 69.0 & 52.1 \\
\hline Birch & & $241.7( \pm 15.2)$ & $7.7( \pm 0.5)$ & 27.3 & 64.1 & 8.0 \\
\hline TM-birch & & $67.6( \pm 4.4)$ & $3.7( \pm 0.3)$ & 65.1 & 44.6 & 69.9 \\
\hline Aspen & Pine tar & $283.6( \pm 13.8)$ & $6.1( \pm 0.4)$ & 36.2 & 64.2 & 20.4 \\
\hline TM-aspen & & $250.9( \pm 25.0)$ & $3.0( \pm 0.3)$ & 68.3 & 60.9 & 44.2 \\
\hline Birch & & $247.1( \pm 18.5)$ & $7.6( \pm 0.5)$ & 27.9 & 52.4 & 10.8 \\
\hline TM-birch & & $95.3( \pm 39.6)$ & $3.1( \pm 0.0)$ & 70.4 & 43.0 & 69.5 \\
\hline Aspen & Beckers & $371.2( \pm 33.9)$ & $6.6( \pm 0.5)$ & 31.1 & 33.6 & 0.9 \\
\hline TM-aspen & & $349.8( \pm 5.7)$ & $4.2( \pm 0.3)$ & 56.2 & 39.6 & 38.0 \\
\hline Birch & & $269.2( \pm 10.7)$ & $7.8( \pm 0.5)$ & 26.3 & 13.6 & 5.9 \\
\hline TM-Birch & & $118.7( \pm 25.6)$ & $3.9( \pm 0.1)$ & 63.4 & 10.9 & 56.4 \\
\hline Aspen & Unimpregnated & - & $9.6( \pm 0.7)$ & - & - & - \\
\hline TM-aspen & & - & $4.8( \pm 0.4)$ & 50.5 & 22.6 & 36.7 \\
\hline Birch & & - & $10.6( \pm 0.5)$ & - & - & - \\
\hline TM-Birch & & - & $4.1( \pm 0.6)$ & 61.0 & 27.3 & 44.4 \\
\hline
\end{tabular}

The oil uptake data are from Ahmed et al. [11]. Unimpregnated samples from non-TM material of aspen and birch are regarded as control $T M$ thermally modified, $E M C$ equilibrium moisture content, $M E E$ moisture excluding efficiency, WRE water repellent efficiency, $A S E$ antiswelling efficiency and $R H$ relative humidity

people performed the visual inspection excluding the edges and heartwood areas.

\section{Statistical analysis}

The experimental data (in the form of a mold grade) were analyzed on the basis of the wood species (aspen and birch), sample type (TM and non-TM) and oil (tung oil, pine tar, Beckers and unimpregnated). To determine the effects of considered factors on mold growth, ANOVA was performed on 104 measurements (considering two flat sides) obtained from the 52 samples of both species. A Duncan post hoc test was carried out simultaneously for all the final evaluation means when the differences in the treatment and performance against mold were more evident. The statistical analyses were performed using $\mathrm{IBM}^{\circledR}$ SPSS $^{\circledR}$ Statistics, Version 20 (IBM Corporation, NY, USA). The significance level was set at 0.05 .

\section{Results and discussion}

\section{Oil uptake}

The results of the oil uptake tests are presented in Table 1. It is evident that the TM aspen and birch had a lower oil uptake than the corresponding non-TM samples. Previous findings also showed that depending on the treatment process, thermal modification could actually lower the liquid absorption $[22,23]$. When the two species were compared, birch, and especially TM birch, had the lowest oil uptake. It is reported that chemical decomposition of birch is more affected than aspen [6] and thus explains why the birch samples had the lowest oil uptake after thermal modification. Among the three types of oils, the Beckers oil had the highest and the tung oil had the lowest uptake. The highest oil (Beckers) uptake was observed in the aspen sample, and the lowest (tung oil) was observed in the TM birch sample.

The anatomical properties of aspen facilitated more oil uptake than for birch [11]. Additionally, the liquid properties of the Beckers oil yielded the highest uptake in both the aspen and birch samples. The anatomical changes of the TM wood, such as vessel shrinkage, cell wall buckling and disintegration of ray parenchyma, may be responsible for the lower oil uptake than in the control as shown in Ahmed et al. [11]. The reason for the high Beckers uptake lies in its formulation (see the 'Experimental' section); Beckers oil contains both non-polar and polar substances. It is believed that non-polar liquids penetrate into the wood by bulk flow, whereas polar liquids penetrate by both bulk flow and diffusion through the wood cell wall [24]. Thus, uptake differences were observed for the tung oil, pine tar 
and Beckers. The amount of pine tar was observed to be higher than for tung oil. Because pine tar uses turpentine as a thinner, the formulation is less viscous and more permeable than tung oil.

\section{Water repellency and dimensional stability}

MEE was illustrated to explain the hydrophobicity of treated wood measured at 65\% RH (Table 1). Equilibrium moisture content of air-dried control aspen and birch was 9.6 and $10.6 \%$, respectively, which decreased after thermal modification and were further reduced after oil impregnation. This indicates that in the same ambient condition, wood impregnated with oil absorbed less moisture and thus had improved MEE. Higher MEE values mean higher hydrophobicity. Thermal modification of wood had noticeable influence on the decrease of EMC which is in agreement with Esteves and Pereira [25].

The samples treated with pine tar or tung oil exhibited the least amount of water uptake compared to the samples treated with the Beckers oil and thus had higher WRE. After $768 \mathrm{~h}$ of soaking in water, impregnated TM aspen samples had somewhat higher WRE than the non-TM samples except for the pine tar treatment. However, TM birch showed the opposite result because TM birch samples had lower oil uptake which resulted in lower WRE values (see Table 1). It is postulated that lower hydrophobicity of Beckers resulted in the lowest WRE in treated wood. The tung oil and pine tar treatment reduced both the rate of swelling and the extent of swelling and thus improved dimensional stability expressed as ASE. ASE is dependent on the volumetric swelling and the effect of volumetric swelling on the samples followed the trend as follows: unimpregnated $>$ impregnated $>\mathrm{TM}>$ impregnated $\mathrm{TM}$ (see Fig. 1). The TM wood was more dimensionally stable than the unimpregnated sample and its dimensional stability was improved further after the oil treatment (see Table 1).

Dimensional stability depends on the extent of, rather than the rate of, water uptake. The water uptake rate was considerably reduced either by introducing thermal modification or by oil treatment as a water barrier and further more improved in combination of two treatments. When wood absorbs moisture from its surroundings, water molecules are inserted between and within the wood polymers (cellulose, hemicelluloses and lignin) forming hydrogen bonds, which causes the wood to swell. During the thermal modification process, degradation of hemicelluloses, modification of lignin, redistribution of extractives, cellulose higher crystallinity content and the reduction of hydrophilic - $\mathrm{OH}$ groups in the cell wall result in a significant reduction in the amount of water absorption $[7,26]$. However, the water repellent properties of TM

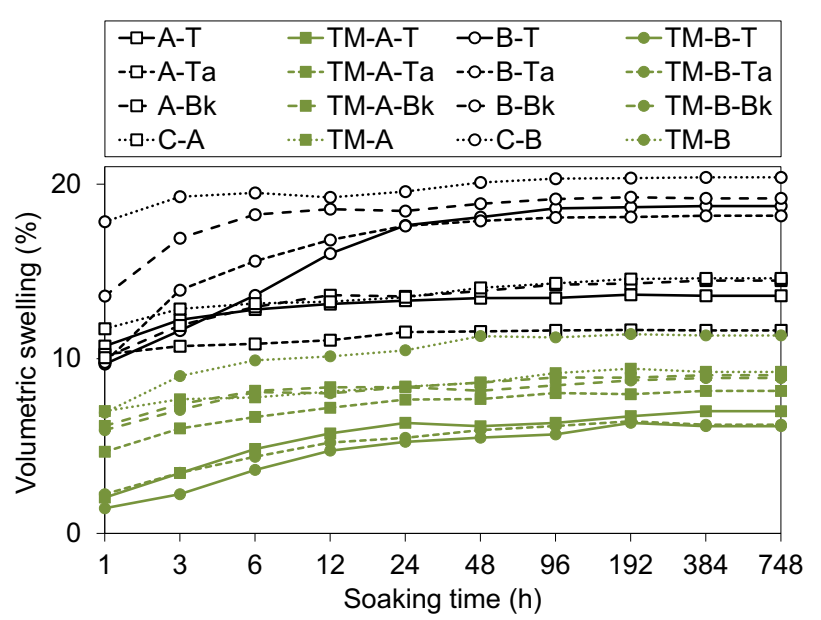

Fig. 1 Volumetric swelling of the thermally modified (TM) and nonTM samples from aspen $(A)$ and birch $(B)$ impregnated with tung oil $(T)$, pine tar $(\mathrm{Ta})$ and Beckers oil $(B k)$ during soaking in water at $21{ }^{\circ} \mathrm{C}$ for $748 \mathrm{~h}$. Unimpregnated samples from non-TM material of aspen and birch are regarded as control $(C)$. Each point is the mean value of five repeated tests

wood could be further improved after oil impregnation during the post-treatment of the modification process. Untreated woods swell more due to their porous structure, whereas the oil-treated samples swelled less due to the deposition of oil in the capillaries and void spaces in the wood. In this context, Ahmed and Morén [10] showed that during the water soaking test, the dimensional stability of $\mathrm{TM}$ and control pine and spruce impregnated with oil was improved compared to the untreated samples. Oil treatments reduced the tendency of the wood to take in moisture (related to the degree of water repellency) and to change dimensions (related to the dimensional stability).

\section{Wet-dry cyclic test}

There was a pronounced reduction in the volumetric swelling of the TM wood, indicating a better dimensional stability over time. By impregnating with oil, the dimensional stability was further improved. As a result of the nature of the leaching process, some of the oil also leached out during the wet-dry cycles, and the dimensional stability of the treated samples stabilized after the 4th wet-dry cycle (see Fig. 2). Overall, the Beckers-treated samples showed the highest leaching loss and volumetric swelling, whereas the tung oil-treated samples showed the lowest. The unimpregnated aspen and birch samples showed the least amount of volume changes during the wet-dry cycle test. Increasing trends in volumetric swelling were observed for the unimpregnated TM aspen and birch samples (see Fig. 2).

To determine the dimensional stability of wood, it is essential to determine how the volume changes over a 


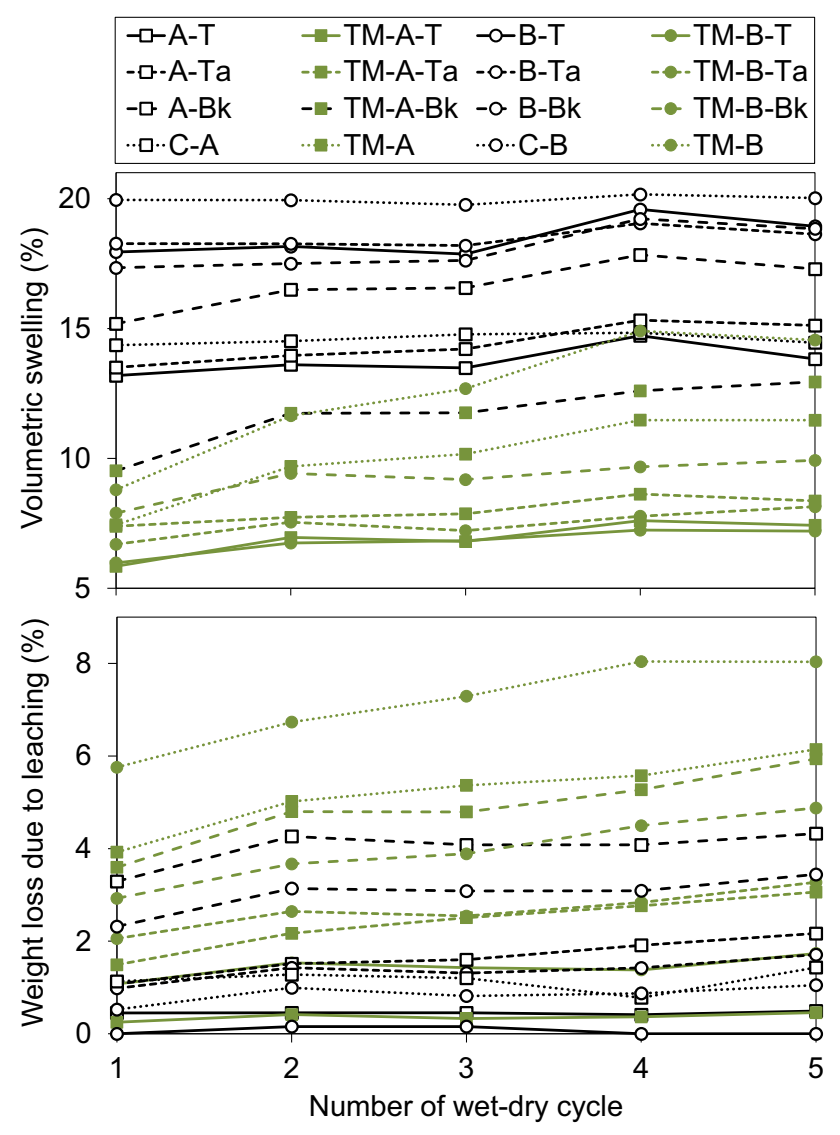

Fig. 2 Volumetric swelling and leaching loss from the thermally modified $(T M)$ and non-TM samples from aspen $(A)$ and birch $(B)$ impregnated with tung oil $(T)$, pine $\operatorname{tar}(T a)$ and Beckers $(B k)$ in the wet-dry cycle test. Each point is the mean value of five repeated tests. Unimpregnated samples from non-TM material of aspen and birch are regarded as control $(C)$

number of cycles. This is particularly important when using the water-soaking/oven-drying method because the oils are susceptible to leaching by water, as evident during the wetdry cycles (see Fig. 2). The water repellent treatment caused macro-pore blocking by depositing hydrophobic compounds in the cell lumens and in general, that deposition takes place in the main penetration paths of the wood [11]. Ultimately it reduces the capillary water uptake. With the pine tar formulation, linseed oil was used as a carrier and is also considered to be a drying oil due to its high polyunsaturated fatty acid content, like linolenic acid (45-70\%) and linoleic acid (12-24\%) or monounsaturated acid, such as oleic acid (10-21\%) [27]. Thus, tar was found to be somewhat resistant to leaching, which resulted in less volumetric swelling and mass loss in the treated wood samples. Furthermore, Beckers is a water-miscible formulation containing approximately $75 \%$ water, which was found to be more prone to leaching, and caused a higher volumetric swelling in the treated wood. However, tung oil was found to be the most resistant against leaching losses and exhibited the best dimensional stability of the impregnated wood samples (see Fig. 2). It has been reported that tung oil can penetrate deep into wood and form an almost permanent seal against moisture [28]. However, for unknown reasons, the birch sample impregnated with tung oil exhibited much higher volumetric swelling. Furthermore, the increasing trend of volumetric swelling for unimpregnated TM aspen and birch samples may be related to the removal of water-soluble carbohydrates/extractives during wet-dry cyclic testing. Comparing between two, birch had higher volumetric swelling than aspen. This could be due the production of more soluble carbohydrates in birch after the thermal modification process [29]. Chemical reactions occurring in the wood during thermal modification mainly account for the increase in dimensional stability. Impregnating these samples with oils (with the exception of the Beckers oil) may permit both the water repellency and dimensional stability to be further improved (see Fig. 2). As the treatment of wood with nonchemically bonded water repellents provides significant control of the water uptake over a reasonable period of time [30], the improvement of dimensional stability could be reduced if the treated materials are exposed to water for a sufficiently long time.

\section{Accelerated mold test}

After 21 days of accelerated mold testing in the climate chamber, the mold growth was visually rated and compared. Figure 3 shows a relative visual comparison for mold growth for the different treatments. The TM birch samples were found to be more vulnerable than the TM aspen samples. Two types of oil (pine tar and tung oil) did not show any inhibitory effects and rather enhanced the mold growth sometimes. The TM birch sample impregnated with the pine tar showed a significant increase in mold infestation compared to the other treatment (see Figs. 3, 4). Above all, it is clear that the thermal treatment of the aspen and birch actually placed the samples at a greater risk of mold growth when subjected to extreme climates. The Beckers showed significantly improved mold resistance for TM samples (see Fig. 4). Birch wood was found more prone to mold than aspen after the thermal modification process. Figure 4 shows the comparison between the different treatments and highlighted the significant differences.

The TM wood studied here indicated that heat treatment did not obviously reduce, but rather accelerated the mold growth on the outer surface of the boards and the result is in agreement with other findings [1]. This effect might be due to the hemicellulose that hydrolyzed into oligomeric and monomeric structures even though it changes the cellulose, hemicelluloses and lignin content $[1,31]$. The 

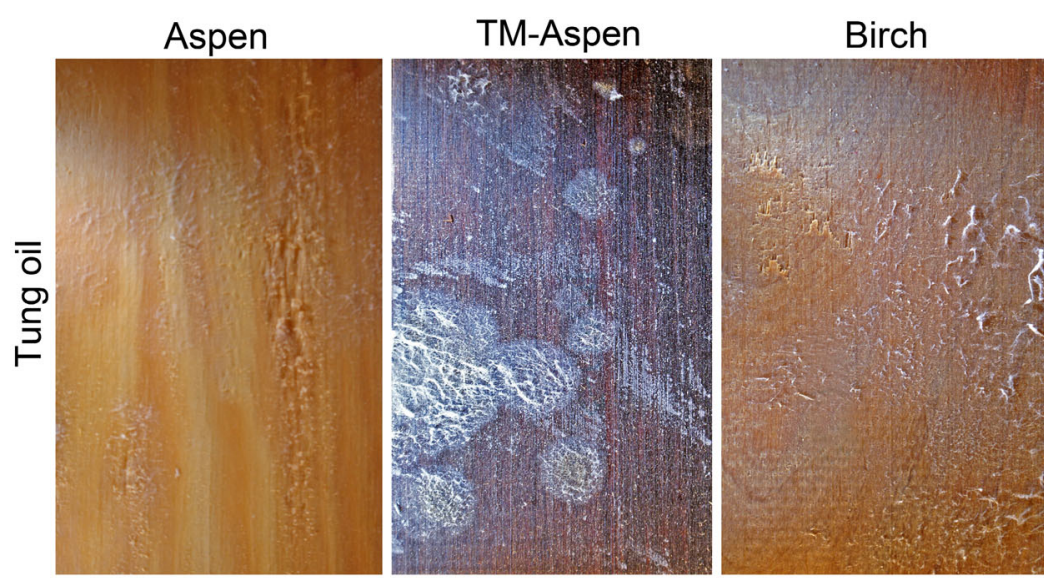

\section{TM-Birch}
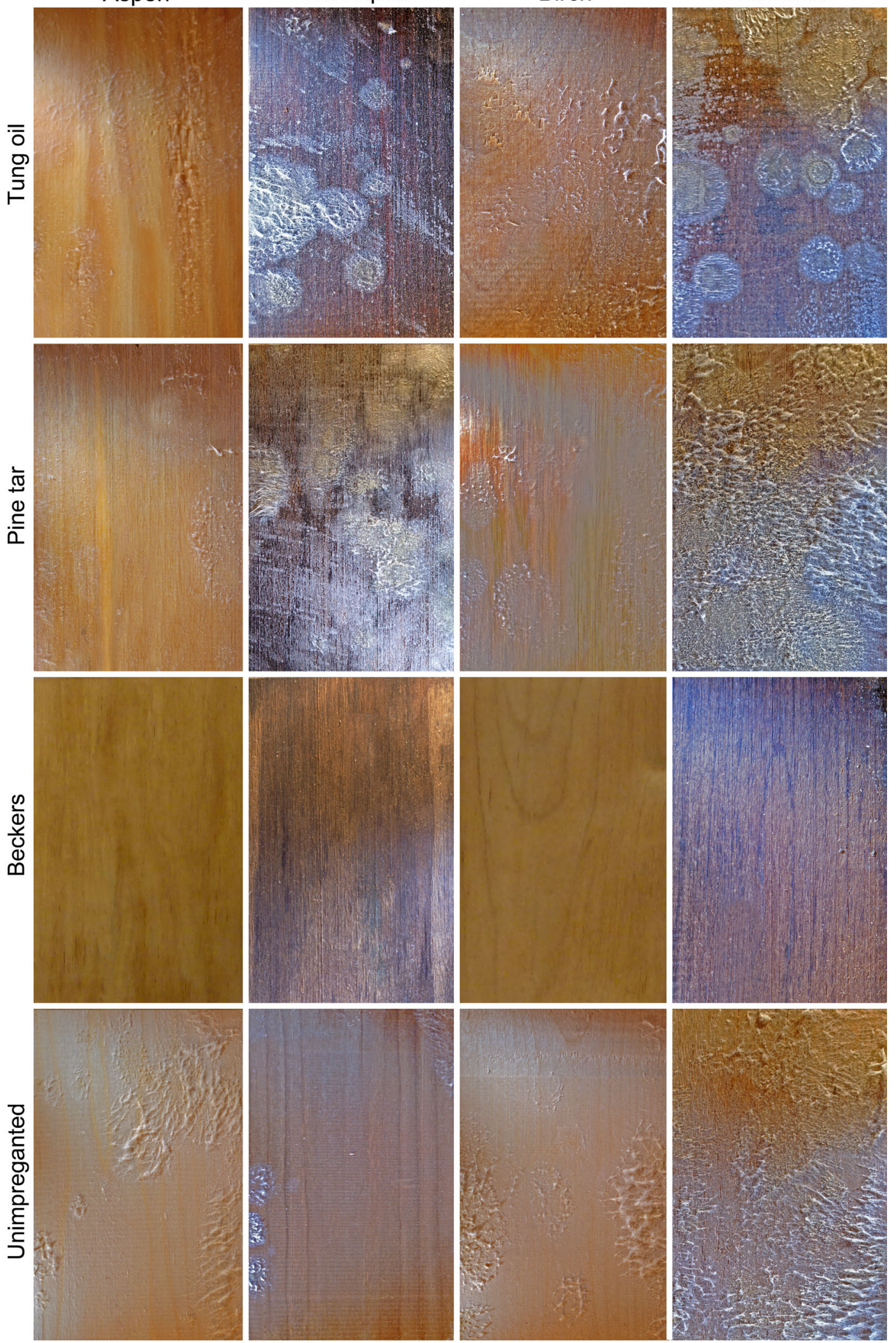

Fig. 3 Comparison of visual mold growth on the surfaces of the thermally modified (TM) and non-TM wood impregnated with three different oils after the accelerated mold test in a climate chamber at

$27{ }^{\circ} \mathrm{C}$ and $92 \%$ relative humidity (RH) for an incubation period of 21 days. Unimpregnated samples from non-TM material of aspen and birch are regarded as control 
Fig. 4 Mold grades of the thermally modified (TM) and non-TM samples impregnated with three different oils after an incubation period of 21 days in a climate chamber at $27^{\circ} \mathrm{C}$ and $92 \%$ relative humidity $(\mathrm{RH})$. Unimpregnated samples from non-TM material of aspen and birch are regarded as control. Vertical bars represent the standard deviations. Different letters indicate a significant difference by Duncan's homogeneity groups $(P \leq 0.05)$

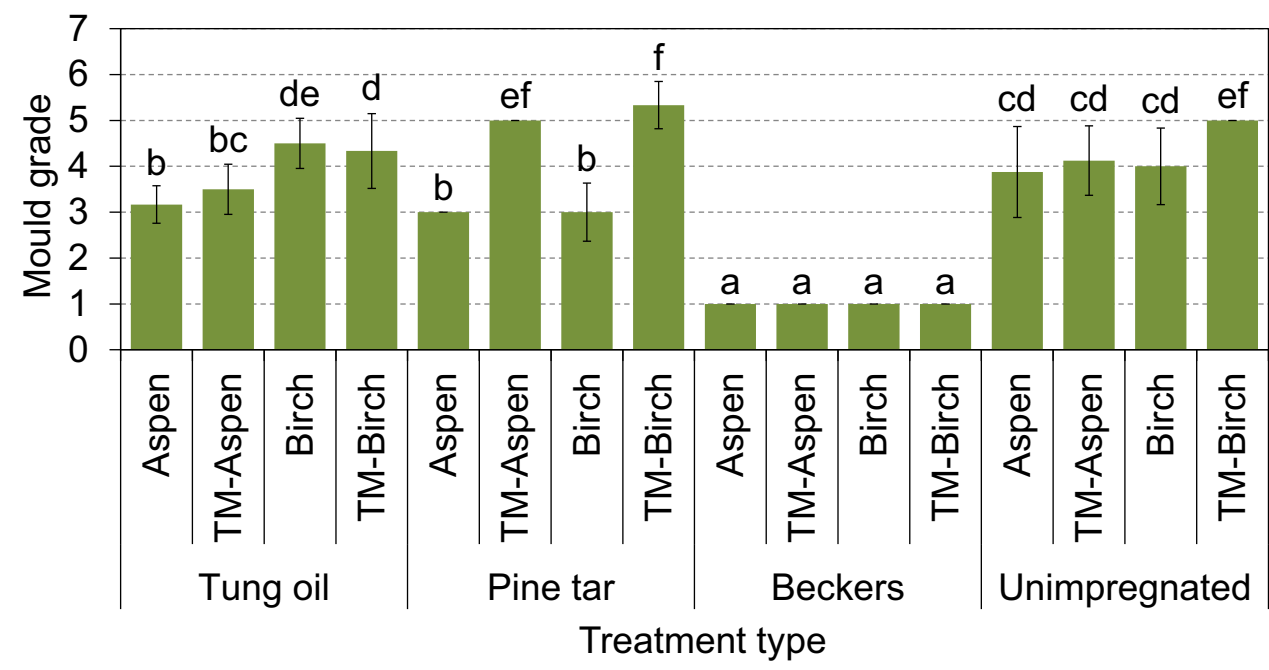

degradation of hemicelluloses that produced soluble sugars may have accelerated the mold growth [19]. Birch has more hemicellulose than aspen and is more affected by the thermal modification process [6], which may have caused the production of more soluble carbohydrates [29], resulting in a larger mold infestation.

It was speculated that because of the diverse nature of the chemical constituents in pine tar, samples treated with it would have some mold resistivity. Pine tar contains acidic constituents, such as tricyclic diterpenoid resin acids, fatty acids and phenols, tricyclic diterpene hydrocarbons and alkylphenanthrenes, along with monoterpenoids and simple phenols [32]. However, when wood was treated with pine tar and subjected to a humid climate, mold growth was observed which is in accord with Egenberg et al. [33]. Using linseed oil in this pine tar formulation is reported to form a food source for the mold fungi [34] and may have accelerated the mold growth. Wood treated with commercial Beckers oil had the lowest mold infestation (see Figs. 3, 4). The reason for this result is the use of biocides, such as propiconazole and 3-iodo-2-propynyl butylcarbamate (IPBC), in the commercial formulation. Propiconazole is reported to be highly effective against a broad range of Basidiomycete fungi and has good stability and leach resistance in wood, and IPBC actively controls nonwood-degrading surface mold for a period of time [35]. Although tung oil is reported to inhibit the effects of certain fungi [22], in the present study, it was evident that it had very little to no effect against surface mold infestation. This natural oil may also serve as a food source for the mold in treated samples. Similar to Beckers, using propiconazole and IPBC in appropriate amounts in tung oil or a pine tar formulation may actually improve durability against mold or other wood decaying fungi.

\section{Conclusions}

Post-treatment with oils, especially tung oil and pine tar, was proven to improve the water repellency and dimensional stability of the treated wood. However, treatments with tung oil and pine tar did not significantly improve the mold resistance. Beckers oil treatment on the other hand, did not significantly improve the water repellency and dimensional stability of wood; it inhibited the mold growth significantly. Thermal modification of aspen and birch actually accelerated the mold growth especially in birch. Because of their low natural durability against mold and good impregnability, the effects of oil treatments may be improved by choosing alternative natural oils based on the end use of the product.

Acknowledgements We wish to express our gratitude to the European Union and the European Regional Development Fund, the County Administration of Västerbotten, the Skellefteå Municipality and the TräCentrum Norr for their financial support.

Open Access This article is distributed under the terms of the Creative Commons Attribution 4.0 International License (http://crea tivecommons.org/licenses/by/4.0/), which permits unrestricted use, distribution, and reproduction in any medium, provided you give appropriate credit to the original author(s) and the source, provide a link to the Creative Commons license, and indicate if changes were made.

\section{References}

1. Boonstra MJ, van Acker J, Kegel E, Stevens M (2007) Optimisation of a two-stage heat treatment process: durability aspects. Wood Sci Technol 41:31-57

2. Kamdem DP, Pizzi A, Jermannaud A (2002) Durability of heattreated wood. Holz Roh Werkst 60:1-6

3. Tjeerdsma BF, Boonstra M, Pizzi A, Tekely P, Militz H (1998) Characterisation of thermally-modified wood: molecular reasons 
for wood performance improvement. Holz Roh Werkst 56:149-153

4. Weiland JJ, Guyonnet R (2003) Study of chemical modifications and fungi degradation of thermally modified wood using DRIFT spectroscopy. Holz Roh Werkst 61:216-220

5. Alén R, Kotilainen R, Zaman A (2002) Thermochemical behavior of Norway spruce (Picea abies) at $180-225^{\circ} \mathrm{C}$. Wood Sci Technol 36:163-171

6. Kocaefe D, Poncsak S, Boluk Y (2008) Effect of thermal treatment on the chemical composition and mechanical properties of birch and aspen. BioResources 3:517-537

7. Bekhta P, Niemz P (2003) Effect of high temperature on the change in color, dimensional stability and mechanical properties of spruce wood. Holzforschung 57:539-546

8. Rapp AO, Sailer M (2001) Oil heat treatment of wood in Germany-state of the art. In: Rapp AO (ed) Review on heat treatments of wood. Cost Action E22. Proceedings of special seminar, Antibes, France, pp 45-62

9. Wang JY, Cooper PA (2005) Effect of oil type, temperature and time on moisture properties of hot oil-treated wood. Holz Roh Werkst 63:417-422

10. Ahmed SA, Morén T (2012) Moisture properties of heat-treated Scots pine and Norway spruce sapwood impregnated with wood preservatives. Wood Fiber Sci 44:85-93

11. Ahmed SA, Sehlstedt-Persson M, Hansson L, Morén T (2013) Evaluation of preservative distribution in thermally modified European aspen and birch boards using computed tomography and scanning electron microscopy. J Wood Sci 59:57-66

12. Ahmed SA, Sehlstedt-Persson M, Morén T (2013) Development of a new rapid method for mould testing in a climate chamberpreliminary tests. Eur J Wood Prod 71:451-461

13. Calonego FW, Severo ETD, Furtado EL (2010) Decay resistance of thermally-modified Eucalyptus grandis wood at $140^{\circ} \mathrm{C}, 160^{\circ} \mathrm{C}$, $180^{\circ} \mathrm{C}, 200^{\circ} \mathrm{C}$ and $220^{\circ} \mathrm{C}$. Bioresour Technol 101:9391-9394

14. Welzbacher CR, Rapp AO (2007) Durability of thermally modified timber from industrial-scale processes in different use classes: results from laboratory and field tests. Wood Mater Sci Eng 2:4-14

15. Feist WC, Sell J (1987) Weathering behavior of dimensionally stabilized wood treated by heating under pressure of nitrogen gas. Wood Fiber Sci 19:183-195

16. Kocaefe D, Shi JL, Yang D-Q, Bouazara M (2008) Mechanical properties, dimensional stability, and mold resistance of heattreated jack pine and aspen. For Prod J 58:88-93

17. Theander O, Bjurman JM, Boutelje JB (1993) Increase in the content of low-molecular carbohydrates at lumber surfaces during drying and correlations with nitrogen content, yellowing and mould growth. Wood Sci Technol 27:381-389

18. Viitanen HA (1997) Modelling the time factor in the development of mould fungi-the effect of critical humidity and temperature conditions on pine and spruce sapwood. Holzforschung $51: 6-14$

19. Ahmed SA, Sehlstedt-Persson M, Morén T (2013) Mould susceptibility of Scots pine (Pinus sylvestris L.) sapwood: impact of drying, thermal modification, and copper-based preservative. Int Biodeterior Biodegrad 85:284-288

20. Rowell RM, Ellis WD (1978) Determination of dimensional stabilization of wood using the water-soak method. Wood Fiber 10:104-111

21. Sehlstedt-Persson M, Karlsson O, Wamming T, Morén T (2011) Mold growth on sapwood boards exposed outdoors: the impact of wood drying. For Prod J 61:170-179

22. Karlsson O, Sidorova E, Morén T (2011) Influence of heat transferring media on durability of thermally modified wood. BioResources 6:356-372

23. Welzbacher CR, Rapp AO (2004) Determination of the water sorption properties and preliminary results from field tests above ground of thermally modified material from industrial scale processes. IRG/WP 04-40279. IRG Secretariat, Stockholm, Sweden

24. Bailey PJ, Preston RD (1970) Some aspects of softwood permeability. II. Flow of polar and non-polar liquids through sapwood and heartwood of Douglas fir. Holzforschung 24:37-45

25. Esteves BM, Pereira HM (2009) Wood modification by heat treatment: a review. BioResources 4:370-404

26. Epmeier H, Kliger R (2005) Experimental study of material properties of modified Scots pine. Holz Roh Werkst 63:430-436

27. Lyon F, Thevenon M-F, Hwang W-J, Imamura Y, Gril J, Pizzi A (2007) Effect of an oil heat treatment on the leachability and biological resistance of boric acid impregnated wood. Ann For Sci 64:673-678

28. Cui W, Kamdem DP (2000) Wood products and wood protection in China. Holz Roh Werkst 58:387-391

29. Karlsson O, Torniainen P, Dagbro O, Granlund K, Morén T (2012) Presence of water-soluble compounds in thermally modified wood: carbohydrates and furfurals. BioResources 7:3679-3689

30. Feist WC, Mraz EA (1978) Protecting millwork with water repellants. For Prod J 28:31-35

31. Tjeerdsma BF, Militz H (2005) Chemical changes in hydrothermal treated wood: FTIR analysis of combined hydrothermal and dry heat-treated wood. Holz Roh Werkst 63:102-111

32. Reunanen M, Ekman R, Heinonen M (1989) Analysis of Finnish pine tar and tar from the wreck of frigate St. Nikolai. Holzforschung 43:33-39

33. Egenberg IM, Holtekjølen AK, Lundanes E (2003) Characterisation of naturally and artificially weathered pine tar coatings by visual assessment and gas chromatography-mass spectrometry. J Cult Herit 4:221-241

34. Williams RS, Feist WC (1999) Water repellents and water-repellent preservatives for wood. General Technical Report FPLGTR-109, Unites States Department of Agriculture, Forest Service, Forest Products Laboratory, Madison, WI, USA, p 12

35. Schultz TP, Nicholas DD, Preston AF (2007) A brief review of the past, present and future of wood preservation. Pest Manag Sci 63:784-788 